\title{
EL IMPUESTO DE CONSUMOS Y LA RESISTENCIA ANTIFISCAL EN LA ESPAÑA DE LA SEGUNDA MITAD DEL SIGLO XIX: UN IMPUESTO NO EXCLUSIVAMENTE URBANO *
}

\author{
RAFAEL VALLEJO POUSADA \\ Profesor de Historia Económica \\ en la Universidad de Vigo
}

\section{RESUMEN}

Este articulo estudia el impuesto de Consumos español durante la segunda mitad del siglo xix. Se fija en tres aspectos del mismo: a), su peso en la financiación de las ha. ciendas locales; b), su importancia en la protesta antifiscal del siglo xIx; y c), su incidencia. Aquí se mantiene la hipótesis de que los motines anticonsumos constituyeron una de las fórmulas recurrentes de la resistencia antifiscal del siglo xIX, pero no la más importante. Ese protagonismo le corresponde al fraude. Se sostiene asimismo que el de Consumos no fue sólo un impuesto sobre el gasto y que en parte se trasladó a la agricultura. Se aportan datos que hacen al menos dudar del carácter exclusivamente urbano que normalmente se le ha atribuido.

\section{ABSTRACT}

This article studies the Spanish Tax on Consuptions during the second half of the 19th century. It focuses on three issues: a), its significance within the funding of local governments; b), its importance to explain the protests against taxation in the 19th century; and c), its incidence. Our hypothesis is that the mutinies against this tax constituted one of the recurring practices of the resistances against taxation in the 19th century, but not the most important, represented by the tax defraudation. It is also indicated that the Tax on Consumptions was not only a tax on expenditure, and was in part transferred to agriculture. We provide some data that question the exclusively urban character that has been usually attributed to this tax.

" Agradezco los comentarios y sugerencias de Francisco Comin, Juan Pan-Montojo (UAM), Abel Losada, Alberto Gago y Jose Carlos Álvarez Villamarín (Universidad de Vigo), asi como de los evaluadores anonimos de la Revista de Historia Económica, que sin duda han contribuido a enriquecer el texto original. La primera versión de este trabajo, presentada al VII Congreso de Historia Agraria (Baeza, 1995), también se ha visto favorecida por el debate de los participantes en el mismo. 


\section{INTRODUCCIÓN}

Las constantes protestas contra el impuesto de consumos, que en más de una ocasión, pasando de las palabras a los hechos, han originado conflictos de orden público, tienen explicación completa en la antipatía que inspira y en los sufrimientos que impone a los vecindarios sujetos a múltiples trabas. Pero si atentamente se analizan, las quejas no provienen tanto de la naturaleza del impuesto como de la forma en que la exacción se verifica $y$ de las perturbaciones que trae a la vida moral de las poblaciones.

Con esta constatación del carácter problemático del impuesto de consumos, y de algunas de las causas del mismo, abria Segismundo Moret el R.D. de 14 de diciembre de 1905 que creaba la Comisión Extraparlamentaria para su transformación, ya que el tributo habia llegado a convertirse en un grave problema nacional'.

Efectivamente, una de los modalidades de protesta más caracteristicas y habitual del siglo XIX fue la rebelión contra el «odiado» impuesto, de la que han dado cuenta no sólo los contemporáneos, sino los historiadores sociales y económicos y los hacendistas actuales, para los que no ha pasado inadvertida. Porque los motines anticonsumos constituyeron un capitulo de la protesta social, al tiempo que una de las fórmulas más reseñables, por manifiesta y recurrente, de la revuelta antifiscal del conflictivo siglo xIX, en el que la resistencia colectiva ante el fisco, explicita o silenciosa, constituyó uno de los capitulos de nuestra sociologia fiscal, como se explicara en el apartado tercero de este trabajo.

La impopularidad del impuesto de consumos se debió a su afianzamiento en la segunda mitad de esta centuria como el principal ingreso para las Haciendas locales, y por ello de difícil sustitución, como se describirá en el segundo apartado de este articulo. También se tratará, en ese mismo epígrafe, de un aspecto menos considerado por los estudios recientes sobre este tributo, como es el de su incidencia sobre el producto agropecuario.

La contribución de consumos fue considerada normalmente como un impuesto urbano, ya que, en la medida en que se repercutia sobre los precios al consumidor, incidia sobre los habitantes de las ciudades, especialmente sobre los trabajadores y las clases medias. Esto puede ser considerado asi, dados los artículos gravados, normalmente de primera necesidad, con una demanda relativamente inelástica respecto al precio, lo que dotaba, asimismo, al impuesto de regresividad. Ahora bien, esta afirmación requiere algunos matices. En pri-

1 Alvarez Rendueles (1976), p. 214. 
mer lugar, de la geografía (urbana-rural) de la recaudación del impuesto no se desprende tan claramente su carácter urbano. En el transcurso de la segunda mitad del xIX, nominalmente pagaron más por Consumos los «pueblos» que las "capitales" de provincia. Sobre este aspecto se aportan algunas cifras en este trabajo. En segundo lugar estaba la caracteristica del hábitat (disperso/ concentrado), que definia la condición de la población gravada (rural/urbana) e influía en la elección de los modos de recaudación. Alli donde el hábitat era concentrado (villas, ciudades), el impuesto, en la medida que gravaba el gasto, tendria un carácter urbano, mientras que donde la población era dispersa, el impuesto no repercutia tanto en el consumo como en la producción, y se convertja en un gravamen doble sobre la renta campesina; aunque, en este último caso, el impuesto pudo ser trasladado a través de los precios al comprador. La cuestión, entonces, es precisar en qué medida hubo una traslación, más o menos completa, de la carga fiscal al consumidor final. Aqui se mantendrá la hipótesis de que bajo determinadas circunstancias, a los productores rurales les fue inviable trasladar, al menos a corto plazo, el impuesto soportado. Esto ocurrio, desde luego, en 1892. Buena parte de los motines anticonsumos que tuvieron lugar este año, fueron protagonizados por pequeños productores que comercializaban directamente parte de sus excedentes en los mercados urbanos próximos, y los indicios existentes hacen pensar que aquellas mismas dificultades se experimentaron en otras coyunturas, como atestiguan otras de las muchas revueltas antifiscales de las décadas finales del siglo XIX, tal y como veremos en la cuarta parte de este trabajo.

\section{LA CONTRIBUCION DE CONSUMOS EN LA SEGUNDA MITAD DEL SIGLO XIX}

\subsection{Los consumos y la financiación de las haciendas locales: un impuesto insustituible}

La reforma tributaria de 1845 combinó la imposición directa de producto con la indirecta. En ésta, las partidas más importantes fueron la renta de aduanas y el impuesto de Consumos. Este último tenía su origen en el Derecho de Puertas establecido por Garay en 1817, que luego será suprimido y vuelto a restituir con la reforma Mon, al lado de la contribución de Consumos, que seria, junto con la contribución sobre inquilinatos y la industrial, la fórmula para sujetar a tributo las rentas urbanas, gravando el consumo de especies determinadas. 
Para su exacción se establecian varias categorias de poblaciones, según su número de habitantes, con tarifas más elevadas a medida que crecia el tamaño de las mismas. Nominalmente, por tanto, la carga fiscal era más elevada cuanto más grande fuese el núcleo habitado, porque, aunque se intentó la fijación de cupos para cada municipio en función de los niveles de consumo, el criterio de los habitantes fue el único que se impuso en la práctica.

El impuesto fue hasta 1874 uno de los motivos del disenso en las familias del liberalismo, por criterios de equidad y de eficiencia. Los progresistas, recogiendo las demandas de las clases populares, los suprimian con las revoluciones políticas. Éstos, en el plano teórico lo criticaban por tres razones: 1), la injusticia en el reparto; 2), las restricciones sobre la libertad de comercio y circulación, y 3), los efectos económicos directos del impuesto. Además, las di. versas fórmulas establecidas para recaudarlos daban lugar a diferencias entre los contribuyentes, $y$ entre unos municipios y otros, con lo que las desigualdades se hacian más evidentes. Por otra parte, su gestion por las autoridades locales lo convertia en uno de los instrumentos fundamentales del mercado politico oligárquico y caciquil, en redistribuidor de rentas a favor de los recaudadores privados del mismo y en centro de la ira popular ${ }^{2}$. Por ello era suprimido en las revoluciones progresistas, cuando los sectores urbanos tendian a ser tratados fiscalmente de un modo más favorable, como constatamos en el Sexenio revolucionario '. Sin embargo, como las haciendas locales y provinciales se financiaban en buena medida a través del recurso a los recargos y arbitrios sobre este impuesto, las necesidades financieras acabaron imponiéndose en las revoluciones de 1854 y 1868 , y el impuesto se restablecio, primero como impuesto local, y más tarde como contribución estatal 4 .

Primó, pues, la suficiencia: el impuesto, sin una reforma del cuadro fiscal y una hacienda local diseñada con autonomía financiera y medios alternativos de ingreso, era insustituible, sobre todo para los municipios y las provincias. $Y$ lo fue más a medida que avanzó el siglo. En 1846 los recargos para atenciones locales supusieron por término medio un $21,2 \%$ de la recaudación total por este tributo, mientras que en 1867 aquéllos suponian ya el 48,6\% (Cuadro 1), y para buena parte de los ayuntamientos, sobre todo aquellos que carecian de

2 Sobre estos aspectos, ver Martín Niño (1981), pp. 222 y ss.; Pan-Montojo (1994a), pp. 222 y ss., y Vallejo (19941, pp. 270 y ss.

3 Los ministros progresistas aceptaban, a veces de mala gana, la supresion de los consumos efectuada por las juntas revolucionarias. La insustituibilidad a corto plazo les llevó incluso a intentar reponerlos, como en el caso de Collado; ver Comin (1988), p. 43 y pp. 157.158; Costas Comesaña (1988), pp. 58.59, y Martin Niño (1972, 1981$)$.

+ Sobre esto, ver Martin Niño (1981), Benaul (1985), Scrrano (1987), Zurita (1990) y Castro (1991). 


\section{CUADRO 1}

Impuesto de Consumos: recaudación y recargos provinciales y municipales (1846-1905)

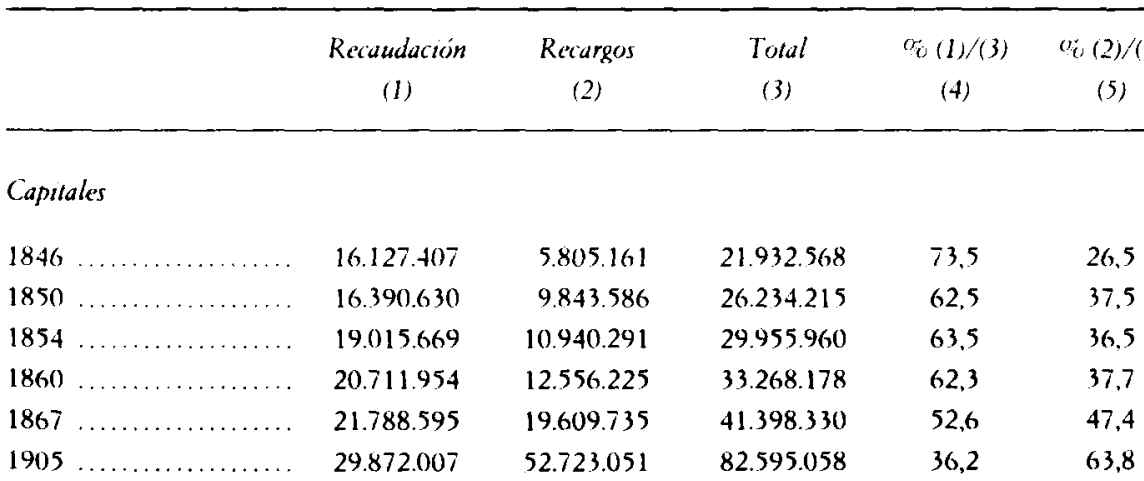

Pucblos

$\begin{array}{rrrrrr}1846 \ldots \ldots \ldots \ldots \ldots \ldots & 20.794 .620 & 4.124 .722 & 24.919 .343 & 83,4 & 16,6 \\ 1850 \ldots \ldots \ldots \ldots \ldots \ldots & 22.078 .988 & 5.121 .012 & 27.200 .000 & 81.2 & 18,8 \\ 1854 \ldots \ldots \ldots \ldots \ldots \ldots \ldots & 22.349 .794 & 8.005 .714 & 30.355 .507 & 73,6 & 26.4 \\ 1860 \ldots \ldots \ldots \ldots \ldots \ldots \ldots & 24.073 .666 & 18.172 .515 & 42.246 .181 & 57.0 & 43,0 \\ 1867 \ldots \ldots \ldots \ldots \ldots \ldots & 49.518 .420 & 47.850 .923 & 97.369 .343 & 50,9 & 49,1 \\ 1905 \ldots \ldots \ldots \ldots \ldots \ldots & 50.214 .926 & 38.573 .989 & 88.788 .915 & 56.6 & 43.4\end{array}$

Total

\begin{tabular}{rrrrrr}
$1846 \ldots \ldots \ldots \ldots \ldots \ldots$ & 36.922 .027 & 9.929 .883 & 46.851 .910 & 78,8 & 21,2 \\
$1850 \ldots \ldots \ldots \ldots \ldots \ldots$ & 38.469 .618 & 14.964 .597 & 53.434 .215 & 72,0 & 28,0 \\
$1854 \ldots \ldots \ldots \ldots \ldots \ldots$ & 41.365 .462 & 18.946 .005 & 60.311 .467 & 68,6 & 31,4 \\
$1860 \ldots \ldots \ldots \ldots \ldots \ldots$ & 44.785 .620 & 30.728 .739 & 75.514 .359 & 59,3 & 40.7 \\
$1867 \ldots \ldots \ldots \ldots \ldots \ldots$ & 71.307 .015 & 67.460 .658 & 138.767 .673 & 51,4 & 48.6 \\
$1905 \ldots \ldots \ldots \ldots \ldots \ldots$ & 80.086 .933 & 91.297 .040 & 171.383 .973 & 46,7 & 53,3 \\
\hline
\end{tabular}

Notas: a) La columna 1 (Recaudación) son Derechos para el Tesoro.

b) Las cifras son cupos y valores recaudados.

Funtes: Anuario Estudístico de España, 1862-1865 (1866-67), p. 770, y Anuario Estadistico de España, $1860-1867118701$. p. 1038.

Comision Extraparlamentaria para la transformacion del impuesto de Consumos (1906) Tomo I, Estado n." 29. 
bienes patrimoniales, constituian la partida más importante de sus ingresos ordinarios. Este papel, no obstante, se acrecentó tras la restitución del impuesto efectuada por Camacho en 1874, una reimplantación que asimismo aumentó el número de especies sujetas a las tarifas oficiales, sometiendo al impuesto bienes de consumo popular antes no gravados, como la sal, las harinas y lo cereales, lo que incrementó su regresividad y repercutió en su creciente impopularidad 5 .

Efectivamente, tras 1874 las decisiones de los gestores locales para hacer frente a los desequilibrios financieros tomaron dos direcciones fundamentales: 1) el recurso al recargo máximo del $100 \%$ sobre las especies sujetas a tarifa, y 2) la ampliación de las especies de consumo sometidas al impuesto, a través de arbitrios sobre especies no tarifadas - como las denominaba la normativa-, que habia de autorizar la administración tributaria. Estos dos últimos mecanismos fueron usados cada vez más por las corporaciones de las ciudades capitales de provincia ${ }^{6}$, pero también por otros núcleos de población con entidad urbana, debido a que los reglamentos sucesivos del impuesto disminuyeron la exigencia de la población minima necesaria para recurrir al sistema de los arbitrios ${ }^{7}$, lo que respondia a las crecientes necesidades financieras municipales, derivadas, entre otras razones, del acometimiento de determinadas infraestructuras y de obras y servicios públicos, como plazas o mercados de abasto, y del aumento del peso de las deudas y sus intereses, asi como de las transferencias a las haciendas provinciales ${ }^{8}$. Constatamos, de esta forma, como los recargos de las

5 Tedde (1984), p. 336; Artola (1986).

- Asi sucedió en Madrid, tras el resurgimiento del déficit en 1877, que obligó desde junio a la adopción de algunos arbitrios municipales, de escaso resultado practico y bastante impopulares, ante las dificultades para recurrir al crédito y la escasa autonomía financiera. Salvadas las di. ficultades impuestas por la administración central para gravar los articulos de comer, beber y arder no gravados por las tarifas oficiales del impuesto de Consumos, el ayuntamiento dio paso, en los presupuestos de 1879.80 y 188(-81, al gravamen de artículos esenciales no incluidos en los encabezamientos; De Diego (1990), pp. 272-274.

- El decreto de 26 de junio de 1874 que aprobaba los presupuestos para $1874-75$, al tiempo que restablecia el impuesto, dispuso que en alas poblaciones que exced[i]an de 40.000 habitantes podr[ia] adicionarse la tarifa con otras especies, poniendolo en conocimiento de la Administración económica de la provinciam, mientras que el Reglamento del impuesto de Consumos de 16 de junio de 1885 señalaba el minimo en 20.000 habitantes (sumando "casco y radion) y el de 21 de junio de 1889 establecia con un caracter general que, cuando «por insuficiencia de los recargos maximos sobre las contribuciones de inmuebles, cédulas personales y consumos, se solici. tasen otros sobre especies $o$ artículos no comprendidos en la tarifa, de cualquiera clase que sean, serán oidas previamente las oficinas provinciales de Hacienda. Sin embargo - se añadia-, los ayuntamientos y las juntas de asociados podran solicitar y obtener arbitrios para cubrir el deficit municipal, aun cuando no hayan utilizado todo el recargo ordinario sobre consumos de vinos». Ver Colección Legislativa (1874, 1885, 1889), tomos CXII, CXIV y CXLII.

- Un ejemplo es el de Pontevedra capital, que en 1885 tenía un presupuesto de ingresos de 
ciudades aumentaron de forma considerable entre 1867 y 1905 (las dos fechas extremas de la segunda mitad del XIX para las que dispongo de cifras sobre los mismos), pues pasaron desde el $47,4 \%$ al $63,8 \%$ del total recaudado. Si en 1867 los porcentajes de recargos sobre el total de consumos era similar en las "ciudades" y "pueblos», en 1905 este peso arrojó un diferencial de veinte puntos a favor de las ciudades (Cuadro 1).

Otro tanto sucedio con los arbitrios sobre especies no tarifadas. Desde el punto de vista legal, el papel de éstos era suplir las insuficiencias de los recargos para financiar las haciendas locales y sus déficit presupuestarios. Es decir, se trataba de un recurso extraordinario. Sin embargo, en la realidad tributaria, la excepción se habia convertido en regla ${ }^{9}$, hasta el punto de que la importancia de estos arbitrios municipales crecía a medida que era mayor el margen no utilizado de los recargos. A través de este mecanismo, lo que sucedió en la práctica fue que en las capitales de provincia se habia extendido la base del impuesto de Consumos, para descargar las especies comprendidas en la tarifa oficial, en perjuicio de los denominados articulos libres, lo que aumento la regresividad de esta imposicion. Esto se debia a que las especies normalmente sujetas a arbitrios, «obran - como explicaba la Comisión consultiva para la reforma de los Consumos- en la imposición de las clases inferiores de la sociedad, más desfavorablemente aún y más en desarmonia con la renta que los ar. ticulos comprendidos en la tarifa oficial, [por lo que] es claro que el mantenimiento del espíritu de la legislación habia sido preferible a esta substitución de los Arbitrios a los Recargos, que en conjunto agrava las injusticias tributarias del sistema oficial de la imposición sobre el consumo" ${ }^{11}$.

En definitiva, el impuesto de Consumos se habia ido afianzando en la segunda mitad del siglo XIX como el principal recurso financiero de los municipios, especialmente los urbanos, a través de los ingresos de los recargos, de los

305.734 pesetas y unos ingresos por consumos estimados en 235.010 pesetas, es decir, el 77 por 100 del total. Por ello, la corporación municipal se oponía al Proyecto de Ley de 5 de marzo de 1885, que pretendia reforzar los ingresos del Estado procedentes de los consumos, a traves de la administracion estatal directa en las capitales de provincia y poblaciones de mas de 20.000 habitantes. El ayuntamiento alegó que el no poder administrar por si mismo el impuesto le reportaria un déficit considerable, ya que no le era "posible aminorar los Gastos, pues la Corporación recurrente, bajo la base de los recursos con que le permitian contar los encabezamientos de consumos, ha contraido obligaciones que no le es dable dejar de satisfacers. La principal era la suscripción de un crédito, por valor de 75.000 pesetas, para ensanche del Campo de la feria y otras obras publicas; Archivo del Congreso de los Diputados, Legajo 219, n." 102. Para la pobreza de las haciendas locales liberales, la insuficiencia de los servicios prestados y la estructura de ingresos y gastos, ver Garcia y Comin (1995), pp. 90 y ss.

"Como se afirma en el informe de la Comision para la transformación del impuesto de Consumos (1910), t. IV, p. 288.

1" Comisión (1910), t. IV, p. 289. 
arbitrios y del denominado beneficio en cupo, que era la diferencia entre la recaudación liquida y la obligación liquida representada por el cupo para el Tesoro ". Tanto era así que, en el ejercicio de 1905 , el impuesto de consumos y los arbitrios autorizados sobre el mismo representaban el 56,5\% de los ingresos realizados por las haciendas municipales ${ }^{12}$. Debido a esta situación, el Dictamen de la Ponencia de la Comisión Extraparlamentaria para la transformación de dicho tributo afirmaba que éste en la práctica se convertía «en un impuesto municipal gravado con un contingente del Estado» ${ }^{13}$. De ahi que el debate sobre su sustituibilidad, abierto a principios del xx, implicó la discusión sobre el modelo de financiación de las haciendas locales.

Este recurso creciente de las ciudades a los Consumos para financiar sus haciendas es un factor de importancia para considerarlos como un impuesto urbano. ¿Pero estamos ante un tributo que sólo repercutía sobre las rentas urbanas? Las evidencias que poseemos no permiten afirmar con total certeza si era más urbano que rural, aunque confirman que también afectaba al producto agrario, y que esta incidencia era sentida como uno de los problemas que agudizó, en determinadas coyunturas, la detracción compulsiva de rentas de la población campesina a través del sistema impositivo, y que esto dio lugar, en los momentos más críticos, a revueltas antifiscales, que tuvieron como ámbito el medio urbano (o más exactamente rururbano) y como protagonistas fundamentales a sectores de la población vinculados a la actividad agraria.

\subsection{La incidencia del impuesto de Consumos}

Determinar en qué medida los Consumos repercutian en las rentas urbanas o en las agrarias resulta dificil, por varias razones. Una de ellas es el carácter equívoco de las estadísticas oficiales de la recaudación del impuesto, que clasificaban los ámbitos territoriales en dos: a), las «capitales» de provincia y «puertos habilitados» (Cartagena, Gijón y Vigo), y b), los «pueblos», donde se

11 Segun la Comisión consultiva (1910), t. IV, pp. 271 y ss., este ultrimo recurso habia ganado una «importancia extraordinaria» en los mecanismos de ingresos municipales por consumos en las capitales de provincia.

12 Calculado a partir del Estado num. 16 del trabajo de la Comisión Extraparlamentaria para la transformación del impuesto de Consumos (1906), tomo 1. Sobre el particular, ver también Domingo Solans (1976), p. 238. Para esta relación entre Consumos y financiación de las haciendas locales, asi como para la limitada aplicación de la Ley de supresión de Consumos de 1911, debido a la presión de los grupos económicos afectados por los gravámenes municipales sustitutivos. véase Martorell (1995).

1 Comisión Extraparlamentaria (1906), t. 1, p. 92. 
comprendian los restantes municipios entre los que se incluian los que, en las regiones más urbanizadas, poseian núcleos de población de verdadera entidad urbana. Si admitiésemos que «pueblos» equivale a rural, las cosas serían sencillas, y podría afirmarse que, desde 1846, los pueblos siempre recaudaron más del $50 \%$ del impuesto, y que desde 1859 su peso fue creciente, hasta $1875 \mathrm{y}$ 1880 , en que ingresaron las tres cuartas partes del total, porcentaje que se moderó en la década de los ochenta y noventa, cuando las capitales superaron la tercera parte de la recaudación total (Cuadro 2).

\section{CUADRO 2}

Evolución de las cantidades pagadas por las capitales de provincia $y$ los pueblos por el impuesto de Consumos (1846-1894)

\begin{tabular}{|c|c|c|c|c|c|c|}
\hline & Año & Capitales & o Total & Pueblos & \% Total & Total \\
\hline 1846 & & 16.127 .404 & $+6,3$ & 18.737 .522 & 53.7 & 34.864 .926 \\
\hline 1859 & & 19.258 .473 & 48,3 & 20.623 .849 & 51,7 & 39.882 .322 \\
\hline 1867 & & 20.325 .218 & 42,7 & 27.315 .630 & 57,3 & 47.640 .848 \\
\hline 1875 & & 15.890 .042 & 23,7 & 51.207 .517 & 76,3 & 67.097 .559 \\
\hline 1880 & & 17.751 .342 & 25,5 & 51.847 .077 & 74,5 & 69.598 .420 \\
\hline 1887 & & 32.026 .781 & 34,8 & 60.077 .531 & 65,2 & 92.104 .312 \\
\hline 1894 & & 27.285 .147 & 39,1 & 42.540 .101 & 60,9 & 69.825 .248 \\
\hline
\end{tabular}

Nota: No se incluyen ni Pais Vascu ni Navarra.

Futentes: 1) 1846: Estadistica Admintstrativa de la Dirección General de Contribuciones, 1855 (1855), p. 276 y p. 294.

2) 1859: Anuario Estadistico de España, 1859 y $1860(1860)$, pp. 345 y 347.

3) 1867 y 1875: Apuntes para el estudio del provecto de ley sobre transformación del impuesto de Consumos (1907), t. 1, pp. 530-531.

4) 1880: Apuntes para el esiudio del proyecto de ley sobre transformación del impuesto de Consumos (1907), t. 1, p. 787.

6) 1887: Archivo del Congreso de los Diputados, L. 244, $n^{\prime} 226$.

7) 1894: Estadística Tributaria de España, 1894-95 (1897).

Otro tanto podriamos decir en términos de impuesto por habitante. En este caso, observamos cómo hasta 1887 la carga fiscal en los pueblos aumentó de forma continuada (aunque con moderación desde 1875), mientras que en las capitales descendió de forma notable en 1875, hasta el punto de que nunca alcanzó un nivel tan bajo $(7,4$ pesetas por habitante), ni la diferencia entre lo pagado por los habitantes de las mismas y los residentes en los pueblos fue tan reducida (Cuadro 3 ). 


\section{CUADRO 3}

Impuesto de Consumos por habitante en las capitales de provincia y en los pueblos (1859-1894)

\begin{tabular}{|c|c|c|c|}
\hline & Capitales & Pueblos & Total \\
\hline \multicolumn{4}{|c|}{ Consumess } \\
\hline 1859 & 19.258 .473 & 20.623 .849 & 39.882 .322 \\
\hline 1875 & 15.890 .042 & 51.207 .517 & 67.097 .559 \\
\hline 1887 & 32.026 .781 & 60.077 .531 & 92.104 .312 \\
\hline 1894 & 27.285 .147 & 42.540 .101 & 69.825 .248 \\
\hline \multicolumn{4}{|c|}{ Poblacion } \\
\hline 1860 & 1.778 .509 & 13.087 .911 & 14.866 .420 \\
\hline 1877 & 2.147 .078 & 13.732 .384 & 15.879 .462 \\
\hline 1887 & 2.387 .195 & 14.358 .616 & 17.560 .352 \\
\hline 1900 & 2.906 .949 & 14.799 .872 & 17.706 .821 \\
\hline \multicolumn{4}{|c|}{ Consumos/babitante } \\
\hline 1859 & 10,8 & 1,6 & 2,7 \\
\hline 1875 & 7,4 & 3,7 & 4,2 \\
\hline 1887 & 13,4 & 4,2 & 5,2 \\
\hline 1894 & 9,4 & 2,9 & 3,9 \\
\hline
\end{tabular}

Notas: a) No se incluven ni Pais Vasco ni Navarra.

b) Las cifras del impuesto de Consumos para las capitales de provincia incluyen estas y los puertos habilitados (Gijón, Cartagena y Vigo). Las cifras de población, solo a las capitales.

Futints: 1) Para impuesto de Consumos: las mismas del Cuadro 2.

2) Para poblacion: censos de poblacion.

Este aligeramiento de la presión fiscal de las ciudades se debió a que el restablecimiento del impuesto por parte de Camacho se vio influido por la virulencia urbana del Sexenio frente a los Consumos. El resultado fue una «desigualdad irritante» entre los cupos de las capitales y los de los pueblos, como manifestaba Celestino Rico en el Congreso de los Diputados en $1876^{14}$, y un incremento de la carga tributaria sobre la producción agraria.

is Diaro de Sestones del Congreso de los Dipulados (DSC), 103, 7-7-1876, p. 2805. Para Rico, esc trato diferencial se debia al comportamiento politico de las ciudades, y tenia como fin mantener el orden publico, lo que era confirmado por el director general de impuestos, López Guijarro. Este, aludiendo al caso de Barcelona, que con Madrid, Valencia. Cadiz y Sevilla, fue la ciudad más beneficiada por la rebaja, reprochaba a Rico saber "perfectamente las consideraciones que 
La presión fiscal real originada por la contribución territorial (rústica y pecuaria) sobre el producto bruto agrario fue de un 2,9 por 100 en 1865 , un 3,2 por 100 en 1870 y un 3,7 por 100 en 1877 , que fue el techo máximo alcanzado en el siglo XIX ${ }^{15}$. Este aumento de 0,5 puntos en tan sólo siete años, producido a partir de niveles de gravamen no alcanzados hasta entonces, constituyó casi una excepción desde 1850. Por tanto, durante los años setenta observamos una relativamente importante presión fiscal dinámica sobre la agricultura ${ }^{16}$.

Otros datos disponibles refuerzan la idea de un basculamiento del peso de los costes públicos hacia este sector económico, tras la Restauración politica y tributaria. Dicho traslado, que ya apuntó en el Sexenio, se debió, por una parte, al aumento del tipo impositivo en la contribución territorial hasta el $21 \%$ entre 1876 y 1881 , que era el más elevado desde la reforma de Mon; por otra, al aludido desplazamiento de los consumos hacia los pueblos. En éstos, como consecuencia del sistema de recaudación, basado mayoritariamente en el reparto, el impuesto se constituía «ni más ni menos que en un recargo sobre la contribución territorial» ${ }^{17}$. Este reforzamiento de la presión fiscal, unido a la reconocida falta de voluntad política para conocer la riqueza agraria y a la ineficacia de la administración tributaria, debió de estimular durante estos años la propensión de los propietarios agricolas al fraude fiscal, como respuesta silenciosa ante las exigencias del fisco, realimentándose de este modo el circulo vicioso en que se desenvolvian las relaciones entre la Hacienda y el mayor número de contribuyentes de la época.

debieron pesar en el ánimo del Gobierno para aprobar el encabezamiento que se fijo a la capital de Barcelona; era en tiempo de la guerra; recuerde S.S. lo que en aquellos dias significaba Barce. lona», DSC, $103,7.7-1876$, p. 2812 . En el reparto de 1875 , respecto al de 1867 , a las ciudades se les rebajaron los cupos en 4,4 millones de pesetas y a los pueblos se les aumentaron en $23,9 \mathrm{mi}$. llones (Cuadro 2).

1 Estas cifras proceden de mi tesis doctoral sobre el fraude fiscal en la España contemporá nea, actualmente en fase de redacción, dirigida por Francisco Comin.

it Los cálculos efectuados por Jesús Sanz sobre los costes de producción por hectarea en el trigo para 1862.1887 apuntan en esta misma dirección. La tributación en este cultivo era en 1862.69 de $5,8 \mathrm{pts} / \mathrm{ha}$, en 1870.74 subió hasta las 8 , en 1875.1879 alcanzó las 8,5 y en 1880.84 y 1885.87 descendió a 8 y 7,2 pesetas, respectivamente; Grupo de Estudios de Historia Rural (1988, p. 49).

1 La cita corresponde a Ángel Escobar en su intervención en el Congreso de los Diputados, DSC; 103, 7.7.1876, p. 2793. Celestino Rico afirmaba en este sentido que, en los pueblos, «alli donde no se saca el impuesto de consumos o por venta exclusiva o por medio de los conciertos parciales, no es más que un recargo sobre la territorial», DSC, 103,7.7.1876, p. 2809. Cándido Martinez sostenia que para los municipios rurales: «La venta a la exclusiva, la venta libre, los arriendos en pueblos abiertos, todo es ineficaz ó deficiente: no les quedan sino los repartos, que convierten esta contribución indirecta en contribución directa; recargan la territorial, pues (...) en todos los pueblos para los repartos se tiene en cuenta la contribucion territorial y se efectuan en proporción a ella y casi comándola como única basem, DSC, 99, 8-7-1878, p. 2842. 
En lo que al impuesto de Consumos se refiere, la situación perduro hasta la primera mitad de la década de los ochenta. Las cifras del reparto territorial de los cupos para 1887 evidencian un aumento considerable de la carga tributaria para los habitantes de las ciudades, que alcanza el nivel más alto de la segunda mitad del xIX, y recupera la diferencia con los pueblos existente en 1859 (Cuadro 3). Esto refleja las medidas correctoras a la desequilibrada situación previa, que observamos ya en el reparto del cupo de Consumos elaborado por Camacho para 1882-83, y la tendencia de los gobiernos, manifiesta en la reforma de Cos-Gayón de 1885, de detraer más recursos de las capitales y de los municipios con más de 20.000 habitantes. En 1894, por el contrario, tanto en los pueblus como en las capitales, la carga fiscal por habitante se aligeró (Cuadro 3). El resultado es que las diferencias entre los valores absolutos del impuesto per cápita de las capitales y de los pueblos tendieron a reducirse entre 1859 y 1875 y entre 1887 y 1894 . Esta evolución de las cifras del impuesto por habitante, si identificamos pueblos con ayuntamientos rurales, evidencian, por tanto, una relativa tendencia hacia la ruralización.

Pero este criterio tan burdo de división territorial de la recaudación es poco satisfactorio para realizar afirmaciones minimamente concluyentes respecto a la repercusión del tributo, aunque, según los testimonios de la Comisión Extraparlamentaria para la supresión del impuesto de Consumos (1906), sus cupos gravaban con mayor intensidad a los habitantes de los pueblos que a los de las capitales. La Comisión razonaba esto en términos de esfuerzo fiscal. Aun cuando no disponia de estadisticas sobre la renta disponible, partiendo de su información sobre el consumo, entendia que, en 1905, la

cuota media (real) por habitante en las capitales es de 10,28 pesetas, y en los pueblos, 3,39 (...). La relación de las cuotas de capitales y pueblos es de 3,032:1; mas como estas cuotas son, como los cupos mismos, liquidas, al llegar al contri. buyente, esa relación se ha mudado en esta otra: 2,341:1. Esta proporción concuerda bastante con la del consumo de carnes: pero como este ultimo sintoma tiende a mostrar una excesiva capacidad de los pueblos, resulta que los cupos gravan a éstos proporcionalmente con más dureza que a capitales (sic) ${ }^{18}$.

Otra forma de conjeturar acerca de la incidencia nominal del impuesto es aproximarse a ella a través de los métodos de recaudación, en particular fijándose en el sistema del reparto, al que acudian la mayoria de los ayuntamientos rurales, dada la inexistencia de centros de consumo en que gravar las transacciones de mercancias. Asi, en 1859 el $58 \%$ de los ayuntamientos acudieron al

18 Comision Extraparlamentaria (1906), t. 1. pp. 100-101. 
método del reparto, mientras que en 1900 el porcentaje fue del $63 \%{ }^{19}$. A su vez, las cifras recaudadas por este procedimiento fueron en 1859 el $33 \%$ del total, mientras que en 1900 ese porcentaje fue del $28 \% 20$. Esos porcentajes constituirian un umbral máximo de la aportación nominal de las rentas del sector agrario al impuesto de consumos, si exceptuamos, claro está, lo ingresado por los «conciertos gremiales».

Ahora bien, una cosa es quién paga nominalmente el impuesto y otra distinta es quién lo soporta efectivamente, en caso de que ocurra la traslación del mismo a los precios. Si el sector agrario estuviese muy mercantilizado, y los bienes fuesen de primera necesidad, con una demanda relativamente inelastica respecto del precio, el gravamen recaeria en su mayor parte sobre el consumidor. No sucedería así si la oferta fuese más rígida que la demanda, y esto es frecuente en algunas épocas del año para determinados productos agrarios, como el vino. En este caso, el impuesto incidiria en mayor medida sobre el productor. Se trata de un hecho que ya observaron los contemporáneos. Asi lo describió Claudio González Zúñiga en 1854:

Los financieros dicen en sus teorias, e impugnan la practica, que la contribución de consumos es de la clase de las indirectas, y el que la paga es el consumidor, mas no asi el productor. Esta distinción no es mas que un sofisma, que para mayor claridad con hechos vamos a demostrarlo. El productor que lleva al mercado sus cereales, caldos y granos para beneficiarlos, y por los que tiene ya satisfechos los derechos en la contribucion territorial, bajo este concepto, es bien claro que los productores, o mas bien dicho, sus productos agricolas deben quedar libres de pagar otro cualquiera impuesto; pero como esto se dice y no se hace, pues que por ellos se les exige cuando los va a beneficiar los derechos de puertas y consumos iquien duda que por este medio en último resultado se le impone a sus productos otra segunda contribucion, que quiza le afecta más que la primera! A este resultado, que puede decirse por lo fácil de su demostración, que es un axioma en economía politica, contestan los financieros no ser exacto, manifestando que esta

14 Vallejo (1994), p. 271. El que en 1900 aumentase el porcentaje de ayuntamientos que recurrieron al reparto hay que atribuirlo a la forma de contabilizar los métodos de recaudación. En 1859, en la fuence mancjada figura el concepto «dos o más medios», uno de los cuales era, sin duda, el reparto. Aquel concepto desaparecio en la fuente utilizada para 1900 . En 1887-88, según un informe enviado el 26-11-1889 por Ramón Cros al subsecretario del Ministerio de Hacienda, los ayuntamientos acudian «en su inmensa mayoria al Reparto, medio utilizado por $6.643 \%$, lo que representaba d $66,6 \%$ de los medios de recaudacion empleados, que se repartian entre la Administración municipal (523) y los encabezamientos gremiales y los arriendos (2.816), Archivo del Congreso de los Diputados, Legajo 247, n." 30. Estos últimos eran los que más recaudaban, Baligand (1956) y PanMontojo (1994a).

211 Esos porcentajes de la recaudacion eran mas elevados en las regiones ruralizadas y' con mayor componente agrario: en Galicia fueron del $50 \%$ y del $39 \%$, respectivamente; Vallejo (1994), P. 271 
contribucion la paga el consumidor, mas no asi el productor, pues que cuando este vende en los mercados sus productos agricolas, tiene muy buen cuidado de exigir con su valor intrinseco la cantidad que por el impuesto debe pagar el consumidor.

En teoria parecerá muy bien el sistema, pero (...) [1]os articulos de consumo de primera necesidad, asi que se les grava con impuestos que no guardan proporción con su intrínseco valor, lo primero que se advierte es la disminución de su consumo 21 .

En definitiva, según González Zúniga, los productores que comercializaban directamente sus productos no podian trasladar todo el impuesto al consumidor. Y otro tanto sucedia cuando la venta era al por mayor. En este supuesto, según dicho autor, durante las negociaciones entre vendedores al por menor y los productores agrícolas, a estos últimos no les quedaba otro remedio que: «Vender sus cereales y vinos a menosprecio por no poderlos estacionar en sus graneros y cubas por el deterioro a que se esponen (sic)», por lo que el impuesto se trasladaba a ellos.

Es más que probable que no siempre las curvas de oferta y demanda fuesen del tipo de las descritas intuitivamente por González Zúniga. En cualquier caso, en función de lo que conocemos sucedió con los Consumos, podemos apuntar las siguientes hipótesis. En primer lugar que, aun con una oferta diferente (más elástica), y una demanda más inelástica que la oferta, no siempre el impuesto fue trasladable en su integridad al consumidor. En segundo lugar, cabe razonablemente suponer que las situaciones de este tipo debieron agudizarse con el impuesto de Consumos en el último cuarto del siglo. Y esto seria asi porque: 1) durante esos años (desde 1874), aumentaron las especies sujetas al impuesto por la tarifa oficial, y estas especies eran bienes de primera necesidad, consumidas por las clases de rentas más bajas; 2) durante estos años también aumentaron los recargos de los ayuntamientos sobre los especies tarifadas y los arbitrios sobre especies no tarifadas, incrementos todos ellos que agudizaron la regresividad del impuesto y, por tanto, repercutieron negativamente en la capacidad de consumo del proletariado urbano, y 3) para los productores/ vendedores al por menor, aun en una situación de demanda inelástica, les sería cada vez más difícil repercutir en los precios tanto los aumentos de las tarifas ya existentes como las nuevas que se establecian. Esta imposibilidad se hizo patente en una coyuntura agraria degradada por la caída de la renta campesina, asociada a la pérdida de mercados en el exterior, a la competencia de productos extranjeros en el interior y a la consiguiente crisis de sobreproduccion; un escenario que se dio, por ejemplo, en 1892, cuando se produjo una

\footnotetext{
2 Gonzalez Zuñiga (1854), Pp. 52.53.
} 
oleada de más de medio centenar de motines, que coincidió en el tiempo con la entrada en vigor de los presupuestos municipales y de los recargos y arbitrios para financiar los gastos y los desequilibrios financieros, y la aplicación de la R.O. de 13 de enero de 1892, que regulaba con detalle la forma de hacer efectivos los arbitrios extraordinarios sobre especies no gravadas en la tarifa de Consumos.

\section{CONFLICIIVIDAD SOCIAL Y RESISTENCIA AN'TIFISCAL EN LA SEGUNDA MITAD DEL SIGLO XIX}

El siglo XIX español constituye una etapa histórica de gran conflictividad. Así lo vieron y lo vivieron los contemporáneos. $Y$ así se presenta cuando uno se acerca retrospectivamente al mismo, tal y como hacía Emilio Riu en 1918. Este periodista y hombre de negocios, al analizar las causas de nuestro atraso industrial, caracterizaba al xIx como un «siglo de guerras civiles, luchas, motines y trastornos», que al generar inestabilidad e incertidumbre constituyeron una de las causas del retraso económico español, ya que «ahuyentaron de nuestro país hombres, iniciativas, capitales, y consumieron un tiempo que fue totalmente perdido (...) [m] ientras (...) las demás naciones trabajaban, aprendian, progresaban y se enriquecian» 22. Además de atinada, la apreciación de Riu dibuja el perfil de la conflictividad de la centuria aqui tratada, cuya descripción nos será util para enmarcar la protesta antifiscal objeto de este trabajo: a) por arriba, la confrontación politica; b) por debajo, la conflictividad social, en la que es preciso incluir, y en un lugar no menor, la resistencia de los ciudadanos frente a la Hacienda pública.

El disenso político está caracterizado en el primer tercio del XIX por la pugna entra absolutistas y liberales, y desde entonces hasta 1874 por las diferencias entre las familias del liberalismo (moderados y progresistas o demócratas), enfrentadas por el modelo liberal a implantar. Tras la frustrada experiencia progresista y liberal del Sexenio revolucionario, surgió un periodo de estabilidad, simbolizado por el pacto del Pardo entre el conservadurismo canovista y el liberalismo turnista de Sagasta. Los conflictos politicos originados por el disenso sobre el modelo liberal desaparecieron. Con ellos, tambien lo hizo el espectro de la confrontación civil ${ }^{23}$. Pero no sucedió así con la conflic-

22 Riu (1918), pp. 6-7.

${ }^{23}$ Esta imagen de estabilidad ha sido subravada por la historiografia; ver Carr (1992), pp. 334 y ss.; Cabrera, Comin y (iarcia Delgado (1989), pp. 13 y ss., o Varela (1994), p. 185. 
tividad y con las demandas sociales, que se profundizaron a medida que avanzaba el siglo ${ }^{24}$ (al tiempo que modificaban su morfologia), por varias razones.

Una de ellas fue el anquilosamiento y la falsificación del funcionamiento electoral e institucional; o, lo que es lo mismo, el divorcio creciente entre la España legal y la España real. Una segunda causa residió en la diversificación de las demandas sociales y políticas, a través de partidos $y$ asociaciones que no sólo no participaban del monopolio liberal, sino que se oponian al mismo $y$ formulaban un modelo alternativo (republicanos, socialistas, anarquistas y regionalistas). En tercer lugar cabe citar la inflexibilidad del sistema real de impuestos establecido en 1845, su desajuste con la vida económica, caracterizado por el excesivo peso sobre el sector agrario, y su crónica insuficiencia, que obligó a echar una pesada carga sobre los impuestos indirectos y al recurso a la deuda, que tendió a monetizarse, con lo que se generó una tensión inflacionista y un ahorro forzoso para determinadas clases sociales, a las que se les trasladaba la factura para financiar las obligaciones del Estado ${ }^{25}$. Un cuarto factor fue la crisis agrícola y pecuaria, que actuó como movilizador social tanto de los productores y propietarios como de las clases populares. En materia fiscal, la crisis evidenció que el sector agrario era el que soportaba un mayor gravamen, y que esta situación no podia seguir asi, mientras otras rentas estaban total o parcialmente exentas, como sucedía con las derivadas del capital mobiliario.

En esta coyuntura critica, los propietarios rurales - y urbanos, cuyos objetivos no siempre coincidieron, hasta el punto de que es preciso diferenciarlos, al menos desde la década de los noventa- formularon demandas de politicas sectoriales, fiscales y comerciales, que favoreciesen sus intereses lesionados por la incidencia de la competencia exterior, a lo que respondió la reforma arancelaria de 1890-1891 26. También demandaron la sujeción a gravamen de rentas hasta entonces exentas, garantizando el principio constitucional de igualdad

24 Mallada (1890, 1994), p. 69, describe esta aparente paradoja en los siguientes términos: «Pues si del lado de la política la tranquilidad es casi absoluta, ipor qué se habla todos los dias del creciente malestar del pais? (...). ¡Ah! Lo sabemos todos. Es que en el orden economico y administrativo vivimos más desconcertados y más intranquilos que nunca".

25 Como explicó Fuentes Quintana (1990), pp. 30 y ss. Sobre la monetización de la deuda, la presion inflacionaria y el ahorro forzoso, ver Sardá (1948), pp. 211 y ss.; Martin Aceña (1985). pp. 262.284), y Comin (1990a), pp. XX.XXI y (1994), pp. 55.56.

26. Segun las estimaciones de Daniel A. Tirado, el sector agrario fue el más favorecido por el arancel de 1891 . Este reforzo la tendencia hacia un mayor proteccionismo de la agricultura frente a la industria, que Tirado (1994, p. 195) constata se venia dando desde la era de los tratados, situación que se mantuvo sin grandes cambios hasta el Arancel de 1906. Esta proteccion diferencial desincentivaria la producción dirigida hacia el mercado exterior y frenaría la reasignación de recursos desde el sector primario hacia la industria. 
ante el fisco, o, en el caso de los propietarios urbanos, que se les preservase del giro, aún timido, pero ya perceptible, de la fiscalidad hacia los sectores no agrarios de la economia ${ }^{27}$, a través de los retoques inducidos en $1892-94$ por Gamazo y la reforma, más amplia y ambiciosa - aunque continuadora de la inflexión iniciada a principios de los noventa-, de Raimundo Fernández Villaverde.

También las clases populares agrarias respondieron a las dificultades. Asi lo hicieron los pequeños propietarios, bien a través de la salida compulsiva de la emigración, bien a travès de diversas fórmulas, más o menos organizadas, casi siempre como respuesta defensiva, para mantener los niveles de renta, amenazados por la competencia en el interior, la caida de los precios, el estrechamiento de los mercados exteriores, el subempleo y el desempleo crecientes y la fiscalidad sobre el sector agrario. La presión fiscal sobre éste derivaba de la contribución territorial, que era elevada cuando no existia fraude fiscal, porque lo tipos nominales superaron desde 1876 el 20 por 100 , y de la incidencia de otros impuestos, como el de Consumos, que podía llegar a convertirse en un sobregravamen sobre el producto campesino, por su forma de exacción. En 1888 era Raimundo Fernández Villaverde quien manifestaba que poseiamos «un sistema fiscal que gravita sobre la riqueza territorial en forma directa, no sólo en la contribución de inmuebles y en la de derechos reales y transmisión de bienes, sino en el mismo impuesto de consumos, que por el encabezamiento y el repartimiento en último resultado viene en mucha parte del pais a traducirse en un aumento, en un verdadero recargo de la tributación directa» 28 . En esta repercusión, los que parece ser llevaban la peor parte eran los pequeños productores que comercializaban directamente parte del excedente agrario, como sucedia en la huerta levantina o en Galicia. En 1906, por ejemplo, el Comité local de la Federación de trabajadores de Vigo sostenia que no era «sólo el encarecimiento de los artículos el inconveniente del impuesto de Consumos. Las formas de exacción establecidas por el Municipio gravan dos veces muchos articulos de consumo. En el extrarradio se cobra el impuesto por medio de reparto, lo que se presta a ciertas venganzas politicas; en el casco ó radio se cobra por medio de casillas ó fielatos, haciendo tributar de nuevo los articulos producidos en el extrarradio ó aldeas del Municipio al entrar para el consumo de la población» ${ }^{29}$.

2) Las estimaciones de Cubel (1994) constatan esta inflexión de la incidencia de la imposicion hacia los sectores no agrarios de la economia desde mediados de la decada de los noventa.

${ }^{26}$ DSC $150,27-6-1888$, p. 4709.

${ }^{24}$ Este testimonio puede verse en Comisión Extraparlamentaria (1906), tomo 2, p. 213. Las diversas modalidades de exacción del tributo introducian una gran complejidad técnica en aquél. 
Los jornaleros del campo experimentaron también la coyuntura agraria depresiva, a través del aumento del desempleo y de la presión a la baja de los patronos sobre los salarios. De esta forma, el movimiento obrero del campo, especialmente el andaluz, adquirió entre 1875 y 1923 gran intensidad y violencia ${ }^{30}$; una violencia que tenia una base estructural en la distribución de la propiedad, y que era alimentada por la dureza de la represión, debida no tanto al temor a una revolución social como al miedo a las subidas de los salarios, que una agricultura mal estructurada dificilmente podria soportar, según Fontana ${ }^{31}$. Esta violencia estallaba en determinadas coyunturas críticas, como fue la crisis de subsistencias de 1879 a 1883 , o las cosechas deficientes y los problemas del empleo agrario en el quinquenio final del siglo y los primeros años del xx, que dieron lugar a una amplia movilización en la que se solicitó pan y trabajo, además de la supresión de los Consumos.

El llamado por los contemporáneos problema de las subsistencias afectó también a los trabajadores urbanos. Los aumentos de precios de bienes de primera necesidad como el trigo y el pan, a partir de 1896, debido a las malas cosechas, a la especulación de los intermediarios, asi como a la protección arancelaria nominal y efectiva, por efecto de la depreciación de la moneda, y a la tensión inflacionista generada por la monetización directa del déficit, unidos a los problemas de desempleo, incidieron negativamente en los salarios reales y en los niveles de consumo. La consecuencia fue una amplia y compleja con-

\footnotetext{
y afectaban a su desigual incidencia sobre productores y consumidores, ya no sólo en un mismo ambito territorial, sino entre los diversos municipios o entre las ciudades y el medio rural. Asi, existian casos de triple gravamen nominal sobre los productores agrarios cuando, por ejemplo, éstos pertenecían a un municipio rural, con el impuesto distribuido a través del sistema de reparto, y comercializaban parte de su producción en otro municipio limitrofe con mercado urbano. En estas situaciones cabria hablar, estrictamente, de sobreimposición por parte de entes territoriales diversos, pues cada uno de ellos tendria «soberania tributaria sobre la misma tenta», tal y como explica Luigi Einaudi (1968), p. 130. Los contemporáneos insistían en que el impuesto de Consumos gravaba al sector agrario doblemente. Asi se constata en las respuestas a la Comisión de la Crisis agricola y pecuaria (1887-1889), como la del Centro proteccionista de la Asociación de productores de España, t. IV, p. 463, la de la Comision provincial de Agricultura, Industria y Comercio de Huesca, t. 2, p. 176, el Consejo provincial de Agricultura, Industria y Comercio de Zamora, t. 2. p. 418, o los Ayuntamientos de A Rúa (Ourense), o el de Pontedeume (Corunia), t. 5 , p. 450 y t. 4. pp. 692-693, por citar solo algunos ejemplos. Torras (1972), p. 158, también constató que durante el Trienio liberal, los forasteros que acudian a los mercados urbanos, cuando habian pagado en su aldea los Consumos por reparto vecinal, contribuian dos veces por el mismo con. cepto. En 1821.1822, como las bases para ese repartimiento eran las mismas de la contribucion territorial rústica, los consumos significaban un recargo sobre el impuesto agrario, especialmente sensible en aquellas comarcas con una agricultura poco mercantilizada; Torras (1972), pp. 159 y 167

30 Calero (1976), p, 28.

3 Fontana (1981), pp. 184 y ss.
} 
flictividad, en la que se unia la lógica del consumidor, que engarza con la tradición (pan barato - el nexo del pan, según la terminologia de Thompson-) y la lógica del trabajador asalariado, que pugnaba por el mantenimiento -o en su caso la mejora- de su poder adquisitivo, del puesto de trabajo o de las condiciones del mismo ${ }^{32}$. Una conflictividad en la que al lado de las huelgas más o menos insurreccionales, las demandas de libre comercio, la rebaja o supresión de determinadas tarifas arancelarias, se repitieron los motines anticonsumos, que ocuparon un lugar central en la protesta de las clases populares de estos años, ya que el impuesto, por su regresividad, agudizaba el alza de los precios de los bienes de primera necesidad ${ }^{33}$. Esta rebeldía influyó directamente en la tendencia hacia la desgravación y supresión del impuesto de consumos, puesta en práctica desde 1893, como lo hizo la articulación de las campañas que, con esta finalidad, promovieron la prensa liberal, republicana y obrera y los partidos liberal, socialista y los republicanos ${ }^{34}$.

Estos hechos también influyeron, a posteriori, para la identificación de los Consumos como un impuesto fundamentalmente urbano, sin reparar a veces en que la mayoria de las revueltas anticonsumos tuvieron lugar en núcleos de población pequeños o medianos ligados a la actividad agraria, y sin atender a si los sujetos de la protesta se manifestaban en calidad de productores o consumidores, o por ambas condiciones. La persistencia de la protesta contra los Consumos contribuyó, por otra parte, a una cierta asimilación de la resistencia antifiscal del siglo pasado con las sublevaciones frente a aquel detestado tributo. No obstante, en materia fiscal, la reacción de los contribuyentes tuvo varias fórmulas individuales y colectivas de expresion ${ }^{35}$.

32 Para la conflictividad popular del 98 , en la que se observan "caracteristicos motines rurales" y protestas de trabajadores. con amotinamientos espontáneos y huelgas más o menos insu. rreccionales, ver Serrano $(1981,1987)$ y Arriero (1984).

"Para solucionar el problema de la carestia de las subsistencias, El País del 19 de abril de 1902 indicaba que lo que el gobierno debía hacer era «imponer el libre cambio, abolir la contribución de Consumos y rebajar las tarifas ferroviarias». El punto de vista de los consumidores y el de los productores se contrapuso claramente durante este periodo, como se constata en las varia. ciones en las tarifas arancelarias para el trigo, que fueron reducidas transitoriamente y repuestas, al vaiven de las crisis y de las peticiones de los grupos económicos implicados.

is El partido liberal incluyo en su programa para 1902 la transformación del impuesto de Consumos; El País inició en 1904 una campaña para su abolicion, secundada posteriormente por El Liberal, El Globo o El Socialisla, en cuyas paginas el PSOE manifestaba «su aspiración a la supresion total del impuesto de Consumos y a la sustitución del mismo por un tributo directo y progresivo sobre la riqueza», El Socialisla, 22-12.1905.

is Fernandez Cainzos (1986), pp. 59 y ss., establece una clasificación de la resistencia antifiscal, donde señala que las modalidades más caracteristicas de las respuestas colectivas son la revuelta fiscal y el fraude organizado. El fraude fiscal es un acto individual, aunque no aislado, ya que forma parte de una disposición colectiva, más o menos extendida según las sociedades, a rechazar deliberadamente el pago de los impuestos. 
Una de ellas consistió en el fraude fiscal, que por su relevancia presupuestaria, debido a las bases imponibles ocultadas y a las cuotas sustraídas a la $\mathrm{Ha}$ cienda, asi como por la inequitativa distribución de la carga fiscal que indujo, fue sin duda la más importante. Otra de aquellas reacciones fue la respuesta organizada a través de asociaciones de propietarios, rurales o urbanos, que actuaron como demandantes de modificaciones tributarias, se anticiparon a las previstas, para influir sobre los tipos, la determinación de las bases o simplemente las figuras propuestas, o respondieron enfrentándose a las reformas fiscales efectuadas. Un ejemplo es el de la Liga Agraria, demandante de política comercial proteccionista para el sector cerealicola y de una política fiscal que rebajase la presión fiscal sobre el sector agropecuario, que tuvo su reflejo en las decisiones tomadas desde 1887 hasta 1900 (Puigcerver, Gamazo sobre todo, y también Villaverde) ${ }^{36}$. Otros ejemplos son el de las asociaciones y ligas de propietarios urbanos, sensibilizadas ante el desgajamiento del impuesto territorial urbano del agrario, la mayor carga fiscal diferencial y la reorganización de la administración tributaria, como consecuencia del establecimiento del Registro fiscal y del Catastro para este tipo de riqueza, o el de las Camaras de Comercio, la Liga de Productores o el de la Unión Nacional (1898-1900), que contestaron la reforma tributaria de Fernández Villaverde. Al mandato de este último al frente de la Hacienda pública correspondieron las más estruendosas huelgas de contribuyentes de la historia contemporanea española, que se concretaron en la negativa al pago de las cuotas trimestrales de las contribuciones, surgida al calor del movimiento asambleario de $1898-1900$ de los propietarios y productores.

El primer capitulo de esa revuelta antifiscal tuvo lugar a raiz de la presentación del proyecto de presupuestos de Villaverde. A partir del 26 de junio de 1899 se efectuaron manifestaciones, cierres de comercios y paros generalizados en toda Espana ${ }^{37}$, como protesta contra su política económica y fiscal, en res-

3. Uno de los objetivos de la reforma de Villaverde fue rebajar los tributos que procedian de la agricultura, lo que explica, según Comín (1988, 1990b), p. 605 y p. 197, la pérdida de peso relativo de la contribución de Consumos, que el ministro consideraba un recargo sobre la Territorial. En lo que respecta a la imposicion sobre el sector agrario, la reforma de Villaverde respon. dia, como las medidas anteriores de Navarro Reverter, a las peticiones de otros subsectores agrarios, como el vitivinicola. Este habia entrado en una coyuntura de crisis múltiple desde 1892 , como explica Pan-Montojo (1994b), pp. 252 y ss. Ante ella, los vitivinicultores se organizaron. o re. forzaron sus organizaciones, para, a corto plazo, influir sobre la politica fiscal y comercial. Son múltiples los ejemplos que se podrian traer a colación. Uno de ellos es el de la comarca del Ri beiro, donde se creo en 1893 una Junta de Defensa, que movilizo a los viticultores; ver Domin. guez (1994). Ante la crisis también se movilizaron los distintos grupos de interés vinculados a la destilacion de alcoholes; ver Pan-Montojo y Puig (1995, p. 260).

r. En Vigo, por ejemplo, se acordo cerrar los establecimientos de once a doce de la mañana 
puesta a la campaña organizada por la Comisión permanente de las Cámaras de Comercio ${ }^{38}$, al tiempo que se producian motines por la carestía de las sub. sistencias, contra el impuesto de Consumos, con incendios de fielatos y asaltos a los ayuntamientos, cuyos protagonistas eran las clases populares. Aunque estos últimos preocupaban al gobierno, mayor preocupación fue la que le produjo la reacción de las "clases productoras», sobre todo a raiz de la primera huelga de contribuyentes, en octubre y noviembre de 1899. Prueba de ello fue su respuesta, expresada en la Circular de la Fiscalia del Tribunal Supremo, de 17 de noviembre, dando instrucciones acerca de los delitos por resistencia al pago de los impuestos, donde se afirmaba que la negativa a satisfacer las contribuciones, «en esa forma llevada a cabo, traspasa los límites de lo licito y cae de lleno bajo la sanción del Código penal» ${ }^{39}$. Ante otras formas de resistencia fiscal, como el fraude, tipificado como delito en el Código criminal desde 1870, la Administración tributaria y los tribunales de justicia habian sido tradicionalmente permisivos, en consonancia con la conciencia fiscal de los grupos dirjgentes de la sociedad española. Pero esta resistencia, a modo de enfrentamiento abierto, cuestionaba la viabilidad financiera del mismo Estado. Por ello se actuaba con una resolución desacostumbrada ante el tipo de contribuyentes protagonistas de la huelga, como se hizo a raiz de la que tuvo lugar entre marzo y mayo de $1900^{+0}$, que fue alentada por la Unión Nacional. La dura ofensiva del Gobierno dio lugar a un acorralamiento de la Unión y, al final, a una contraorden del Directorio de ésta, el 11 de junio de 1900, para que se pagasen los impuestos, cuando dicha organización, por esta y otras razones, se desintegraba. Con ello se cerraba uno de los capitulos más reseñables de nuestra sociologia fiscal ${ }^{41}$, en la que, de todos modos, han destacado por su persisten-

del 26 de junio, aen señal de adhesión a la protesta que presenta al Parlamento la Comision permanente de las Camaras de Comercio. contra los presupuestos»; Archivo de la Cámara Oficial de Comercio, Industria y Nanegación de Vigo (AC(C.IN), Varios, Carpeta 2, n.". 41. Elcuterio Alonso Martinez, presidente del Circulo de la Unión Mercantil e Industrial, se habia dirigido el 7 de mayo a la Camara de Comercio de Vigo, solicitándole que recomendase telegraficamente a los diputados y senadores del Distrito que apoyasen y defendiesen las demandas del Círculo de la Union Mercantil, en contra de los provectos del ministro de Hacienda. apoyo que redundaria eten beneficio de las clases contribuyentes directamente amenazadas», ACOCIN, Varios, Carpeta 3, n." 20.

38 Era uno de los costes politicos de la estabilizacion. González Besada (1902), pp. $781-782$ y 784.785, que fue subsecretario de Hacienda con Villaverde, señaló al respecto que los que no se habian opuesto a la guerra, ni extrañado por la forma de financiarla, no querian asumir ahora los costes de la misma.

${ }^{34}$ Ver Colección Legislativa (1899), pp. 515-517.

4) En Barcelona, el capitán general. Manuel Delgado, proclamaba el estado de sitio y el sometimiento a juicio sumarisimo a quien no pagase los impuestos; Gil Novales (1986), pp. 143. 144.

"Sobre las huelgas de contribuyentes de 1899 y 1900 , pueden verse el libro de Pirretas 
cia, y por sus implicaciones politicas y sociales, las rebeliones frente a los Consumos, que constituyen otra de las grandes modalidades de protesta antifiscal del siglo XIX, cuyos protagonistas nos ayudan a entender en parte sobre quién incidia el impuesto.

\section{LOS MOTINES CONTRA LOS CONSUMOS EN 1892: UNA PROTESTA AGRARIA}

El impuesto de Consumos implantado con el sistema fiscal de 1845 pasó básicamente por tres fases durante la segunda mitad del siglo xIx. En la primera, que llega hasta 1874, este tributo constituyó uno de los factores del disenso político entre las familias del liberalismo español. Los liberales progresistas y demócratas lo repudiaban teóricamente, y los pronunciamientos revolucionarios eran aprovechados para su supresión. Así sucedió en 1846, cuando una insurrección liberal suprimió en Galicia el recién estrenado sistema tributario, y en las revoluciones de 1854 y $1868^{+2}$. La experiencia del Sexenio, saldada con la descomposición de las haciendas locales y un notable déficit acumulado en la del Estado, enseñó, no obstante, que el impuesto era insustituible. Se entraba asi en una segunda fase, que alcanza hasta 1893, aproximadamente. La Restauración política fue acompanada por la restauración tributaria, y al consenso sobre el modelo político liberal se añadió la aceptación plena del modelo fiscal de 1845. Del impuesto de Consumos preocupó ahora su diseño técnico y los problemas de su incidencia, tanto territorial como social, que salian a la luz pública de forma recurrente debido a los motines contra los mismos.

A partir de 1893 se inició una nueva etapa, caracterizada por la tendencia hacia la desgravación de los bienes de primera necesidad ${ }^{43}$, seguida desde 1901 por el debate sobre su sustitución, y desde 1905, sobre su supresión y la modificación de las Haciendas local y estatal. El impuesto era ahora indefendible por su extremada regresividad, demostrada estadísticamente por la Comi-

(1900) y las páginas que les dedicaron Tallada (1946), pp. 167 y ss., Romero 1989) o Tunón (1986), pp. 171 y ss.

42 Para las medidas fiscales de la insurrección liberal de Galicia en abril de 1846 , ver Valle. jo (1994), pp. 265-266. La supresion de los Consumos era uno de los objetivos politicos y económicos formulados durante la intensa movilización social del Sexenio, Perez Ledesma (1988), p. 684 .

13 Según Gabriel Maura Gamazo, «muy singularmente desde 1893 (con breves interregnos), es mas franca y mas constante, parece tambien mas seria la tendencia legislativa a suprimir gra. dualmente y por especies el impuesto de Consumos, porque a esa obra colaboran también los conservadores, que hasta estos últimos años se consideraban forzados a deshacer la labor reformista del partido liberalm, Comisión Extraparlamentaria (1906), t. 2, p. 298. 
sion consultiva para su transformación, y por sus altos costes de gestión, que se aproximaban a las cifras que efectivamente ingresaban el Tesoro y los ayuntamientos por el mismo ${ }^{4 t}$. Esta vinculación de una y otra Hacienda a través de los Consumos, unido a la preocupación politica por el problema de las subsistencias, devolvió por tanto el impuesto al centro del debate político y fiscal sobre los modelos alternativos de Hacienda. Los Consumos ya no sólo eran una cuestión social, como lo fueron en el ültimo cuarto del siglo XIX.

Efectivamente, tras la restauración del impuesto en 1874 , se sucedieron las protestas antifiscales más o menos espontáneas de las clases populares contra la contribución de Consumos. Esta contestación estuvo motivada no tanto por las modificaciones en el tributo que aumentasen los fondos que el Tesoro habia de percibir, como por las atribuciones otorgadas a los ayuntamientos para recargar las especies sometidas a tarifa, hasta el limite maximo del 100 por 100, y la posibilidad de recurrir al establecimiento de arbitrios equivalentes sobre especies no tarifadas, cuya recaudación revertia sobre todo a las haciendas locales. Estos recargos y arbitrios municipales sobre las especies de consumo afectaron a la población de los núcleos urbanos, pero también a los habitantes de lo que, en términos de la administración del tributo de Consumos, se denominaba «extrarradio", asi como a los de otras poblaciones limitrofes no pertenecientes al término municipal, pero que comercializaban sus productos en el mercado local.

Estamos aqui ante el problema de la incidencia del impuesto, una incidencia que las revueltas populares ante el mismo nos ayudan a desvelar. Asi, sus protagonistas nos hacen al menos dudar sobre el carácter puramente urbano que suele atribuirse a los Consumos. A pesar de que las fuentes y los estudios existentes sean poco explicitos respecto a los sujetos activos de las mismas, sabemos que éstos procedieron en distintas ocasiones del medio rural. En los motines anticonsumos de 1885 , suscitados por la Ley de 16 de junio, que establecia para las capitales de provincia la administración directa del impuesto por el Estado, protestaron los habitantes de las ciudades, pero también la

t+ En el Resumen general del informe de la Comision consultiva para la transformación de los Consumos (1910), t. IV, p. 378, se afirmaba no ser excesivo "cifrar los conceptos de administración, cobranza, beneficio de arrendatarios y filtraciones en 100 millones de pesetas anuales». Segun Baligand (1907, 1956), p. 192, «en ningun otro pais ha habido tantas reformas que no han alcanzado exito, en ninguno la reforma es tan necesaria y urgente como en España, que soporta los impuestos de consumo estatales más elevados, gravados ademas con recargos municipales muy considerables, y padece al mismo tiempo el inconveniente de un sistema de recaudación que no es equitativo y resulta muy costoso». En este sentido, Baligand (1956), p. 205, estimaba para 1905 una carga bruta por impuesto de Consumos, recargos y arbitrios de 340,9 millones de pesetas y unos rendimientos para el Estado y los municipios de 155,7 millones. El de Consumos era, como vemos, un impuesto claramente ineficiente. 
«gente del campon; el 30 de noviembre de 1894 fueron los vecinos de once parroquias de Cangas de Tineo (Asturias) los que destruyeron las casetas de Consumos; en junio de 1897 serian las "clases agricolas" las que se levantaron contra el nuevo presupuesto en Fuentevaqueros (Granada), y el 11 de junio de 1900 fueron los huertanos que solian ir a la capital con sus mercancias los que iniciaron y participaron más activamente en la protesta de Murcia th. 'Iambién sabemos que entre 1895 y 1905 , la mayoria de los motines contra los Consumos y las crisis de subsistencias tuvieron como ámbito «los núcleos secundarios ligados al campon ${ }^{46}$, aunque los estudios que conozco no precisen si los que protestaban lo hacian en calidad de consumidores o de productores. Este mismo ámbito de la protesta fue el que predominó en 1892, cuando una oleada de motines recorrio buena parte de la geografia española, afectando a más de medio centenar de poblaciones durante los meses de verano, al entrar en vigor los presupuestos municipales para el siguiente año económico ${ }^{4}$.

En estos motines, aun cuando las fuentes manejadas para su estudio no sean siempre suficientemente explícitas, se constata una importante participación de campesinos que vendian parte de su producción en el mercado local. En los partidos de Espinardo y Churra, por ejemplo, fueron «huertanos» los que protestaron contra el impuesto de Consumos ${ }^{48}$, y en Moratalla, también en la provincia de Murcia, los que intervinieron en los alborotos fueron principalmente "aldeanos» 4". La prensa reconocia que existia una gran agitación en. tre la población de la huerta murciana ${ }^{50}$, provincia en la que se produjeron al menos ocho motines contra los Consumos. Otro tanto sucedió en Villanueva del Grao (Valencia), en donde protestaron las «hortelanas», y en la ciudades de Pontevedra, Vigo y Orense. En Pontevedra fueron las vendedoras de leche y de pescado, que acudian a diario a la plaza de abastos desde las localidades más próximas, las que protagonizaron la protesta por la subida y ampliación de las tarifas de Consumos ${ }^{51}$. En Vigo las que participaron en lo que la prensa

15 Gil Novales (1986), pp. 82, 116 y 125; Arricro (1984), pp. 234.235

to Arriero (1984), p. 216.

ti Vallejo (1990), p. 7

4 El Imparcial, 11-7.1892.

19 El Pais, 3-8-1892.

so La Unión Republicana (Pontevedra), 11-7.1892; Gil (1986), p. 99.

"In Almeria capital, que "venia atravesando de mucho tiempo una crisis gravisima», también se declararon rebeldes los pescadores ante el impuesto de Consumos, decididos «a no botar las embarcaciones, habiéndose presentado (...) al comandante de Marina, para expresarle que les era de todo punto imposible continuar ejerciendo esta industria con tales impuestos", El Pats, 6.7-1892. En la misma fecha tuvo lugar otra protesta contra el nuevo arbitrio municipal de pesas y medidas, $y$ fue protagonizada por vendedores de frutas y aves, verduleros y verduleras ambu- 
local denominó «huelga de las lecheras» también fueron las mujeres. Allí el conflicto estalló el 2 de agosto, aunque hacia ya varios dias que en las aldeas limitrofes venía haciéndose una campana contra los arbitrios municipales, llamando a «la rebelión a las pobres vendedoras de leche y otros artículos sometidos al impuesto de consumos en esta ciudad» 52. En Orense, por su parte, que era una provincia vinicola castigada por el mildiu, donde se esperaba una pobre cosecha para 1892 , lo que hacia presagiar dificultades a los labradores para hacer frente a sus obligaciones fiscales, las vendedoras y una muchedumbre compuesta de «paisanos que acudieron de los pueblos inmediatos» a la capital, fueron los que se resistieron en aquélla al pago de un arbitrio municipal sobre los puestos públicos, que se traducia en un doble derecho de Consu$\operatorname{mos} 53$.

La geografia y los protagonistas de estos motines demuestran, por tanto, que el impuesto de Consumos también incidia en el producto agrario, y que a los campesinos, particularmente los que comercializaban sus productos en el mercado local, les era dificil trasladar, en determinados circunstancias, el tributo a los precios al consumo. Esta imposibilidad - probablemente motivada por una coyuntura alcista de los precios al por menor y al por mayor, desde 1890 - ${ }^{54}$ está confirmada por varios hechos, como la contestación inmediata de los propios consumidores ante la repercusión del impuesto de Consumos. Asi sucedió en uno de los episodios del motín antifiscal de la ciudad de Orense de 1892. Alli, desde el amanecer del domingo día 11 de septiembre, «se notaba una grandísima excitación en la plaza de Abastos. Poco tiempo después, y con motivo del aumento en el precio de la leche, se promovió un grandísimo alboroto. Las compradoras se rebelaron contra ese aumento, rompiendo las cántaras de la leche y amotinándose contra las vendedoras. Éstas, ante

lantes, El Liberal, 6.7-1892. Contra un impuesto similar también se levantaron los marineros de Garrucha (Almeria), El Liberal, 4-7-1892.

"2 La Correspondencia Gallega (Pontevedra), 1.8.1892.

"El Pais. 11-9-1892.

it Los precios al por mayor aumentaron desde 1890 a 1892 (indices $100,104,8$ y 107,8, respectivamente), segun el indice de la Comisión del Patrón Oro; ver Sarda (1948), p. 307. España se separaba, a partir de 1890, de la fucrte caida internacional de precios. Esto se debia, según Sardá (1948), pp. 313-314, a la fluctuación del cambio de la peseta, que se deprecio, al aumentó de la circulación fiduciaria y a las medidas proteccionistas del gobierno Cánovas. Otros indices. como el de precios al por menor en Madrid, confirman un incremento notable de precios entre 1890 y 1892 (indices 100, 116,7 y 124,5 respectivamente; ver Paret (1914), p. 242, y Garcia Alix (1907), p. 300. Donde no existe coincidencia es en las explicaciones sobre las causas desencadenantes del alza. Garcia Alix (1907), p. 312, lo atribuia a la escasa productividad agraria y a las prácticas oligopolicas de los intermediarios. Paret (1914), p. 243 y p. 267, por el contrario, res. ponsabilizaba fundamentalmente a «la mala moneda y el proteccionismom, sin descartar otras va. riables, como los derechos de consumos y los impuestos interiores. 
tal actitud de las amotinadas, se vieron obligadas a vender la leche al precio establecido antes del aumento" "s. En otros lugares, como en Valencia y en Vigo, la respuesta de los productores-vendedores ante el aumento de la imposición fue trasladar los mercados a las afueras de la ciudad, de forma que fuesen los compradores quienes pagasen las nuevas tarifas al cruzar las casillas de fielatos ${ }^{56}$.

Además de estas respuestas, que atendian al intento de traslación del impuesto, esta protesta antifiscal tuvo los rasgos de los tumultos, y ofreció todos los matices y características de las formas de protesta tradicionales: 1) la espontaneidad, aunque con una previa e inorgánica concertación de voluntades, en la que desempeñó su papel el rumor; 2) el protagonismo y el liderazgo de la mujer entre los agentes de una protesta, donde encontramos al campesinado de las inmediaciones de los núcleos urbanos; 3) la violencia selectiva contra todo lo que personificaba y sintetizaba la odiosidad del impuesto; 4) la ausencia de politización en sentido estricto: no eran motines asociaciados a revoluciones políticas, aunque en el discurso de los que protestaban se observaba una interacción de elementos tradicionales o inherentes (actitudes mentales, puntos de vista sencillos) e ideas derivadas (discursos elaborados), no siempre fáciles de distinguir ${ }^{57}$; 5) una mayor complejidad de la protesta en el medio urbano, donde existia una cultura social y politica más desarrollada, aunque con encabalgamiento de formas más arcaicas y modernas. Así, en algunas de las ciudades la protesta tradicional se combinó con la huelga, y de una forma se transitó a la otra ${ }^{58}$, y 6) por último, constatamos un sentimiento de justicia

"El Pais, 13-9-1892.

5o En Valencia, las verduleras del Grao, para no pagar en este caso el arbitrio de pesas y medidas, habian adoptado, segun El País, 6.8.1892, una «actitud que da el mismo resultado que el motín sin el escándalo y el ruidom ya que «instalaron el mercado, muy bien surtido por cierto, en un campo (...) y alli ha acudido el vecindario a proveerse de comestibles». En el caso de Vigo, La Correspondencia Gallega de 5.8.1892 afirmaba uque las aldeanas han manifestado su proposito de establecer el mercado fuera del radio de la población para que sean los consumidores los que pa guen el impueston.

97 Esta linea de contornos poco precisos es la que, según Rude (1981), pp. 33 y ss., se percibe en la ideologia de la protesta popular durante la transición a la sociedad industrial.

58 Asi sucedió en el Grao (Valencial y en Vigo; ver La Unión Republicana (Pontevedra), de 3.8-1892 y 4.8.1892. La relación entre desarrollo económico y comportamiento politico ha sido puesta de manifiesto por los sociólogos del desarrollo, como Robert A. Dahl. Para el caso español, Tortella (1994), p. 27, señaló la relación entre el relativo estancamiento económico del XIX y el estancamiento politico. El reflejo de la base agraria del pais, y de su transición hacia la modernización económica, en la persistencia de las formas tradicionales de protesta y en la coexistencia de éstas con otras más modernas, fue resaltado por Arriero (1984), pp. 193 y 210; Vallejo (1990), pp. 3-6, y 25.26, y Castro (1991), p. 110 
alentando la protesta, que surgia del estado de necesidad al que habia conducido la situación económica y la sobrepresión fiscal ${ }^{59}$.

En ese sentimiento encontramos también el entronque de estas protestas con las tradicionales, con aquello que Thompson denominó la ética popular que sanciona la acción de la muchedumbre ${ }^{60}$. De esa misma legitimidad formaba parte, a finales del siglo xix, el descontento larvado o manifiesto de la mayor parte de la población, que era campesina, la cual, a través del fraude fiscal o por medio de los motines antifiscales, respondia ante una Hacienda pública cuya estructura de ingresos estaba divorciada de la realidad económica española y era cada vez más regresiva, lo que fue acentuado por la deficiente gestión tributaria. Aquella regresividad respondia, social y politicamente, a los intereses oligárquicos de la minoria que gobernaba el pais y obtenía directa o indirectamente rentas a través de la actividad presupuestaria, utilizando el sector público como un administrador de privilegios ${ }^{61}$.

\section{CONCLUSIONES}

Determinar la incidencia real de un impuesto no siempre es fácil. Esa dificultad se acrecienta en un estudio histórico, cuando además nos encontramos con una contribución, como la de Consumos, que debido a los distintos modos de recaudación podia ver alterada incluso su naturaleza de impuesto nominalmente indirecto.

Respecto a los Consumos se ha insistido, no obstante, en su condición de impuesto urbano. En esta idea han influido dos factores. Uno de ellos es que, por su incorporación en los precios al consumo de los bienes de primera necesidad, incidia con mayor presión en los asalariados de las ciudades. El segundo es que los núcleos de entidad urbana aparecian como el marco físico en que

${ }^{9}$ El País, 1-8.1892, afirmaba que los que protestaban iban «armados de su derecho, el derecho a la vida; y de una gran fuerza, la desesperacion». El conde de Xiquena, refiriendose al motin.de Madrid del 2 de julio, sostuvo que: ael recargo a los vendedores era de tal cuantía, que venia a ser abrumador e insoportable para esta clase, que, acosada por la miseria, no tenía más remedio, en la lucha por la existencia, que morir de miseria o lanzarse a la calle», Diario de Sesiones del Senado, 218, 2-7.1892, p. 4211.

6) Sobre la ética popular que sanciona la acción directa de la muchedumbre, la cual se fundamenta en un uso social de las clases populares que Thompson denominó ueconomia moral de la multitud", ver Thompson (1979), pp. 89 y ss.

61 Como denuncio, entre otros, Garrido (1881). La busqueda de rentas a través del sector público resulta frecuente en los paises atrasados, donde existe una distribución muy desigual de la riqueza, de la cultura y del poder, como sucedia en la España del xix. Sobre los costes para la sociedad de este comportamiento, ver Garcia Vinuela (1995). 
se desarrollaron las múltiples rebeliones contra aquel tributo durante la segunda mitad del XIX, asociadas en 1854 y 1868 a las revoluciones que implantaban el liberalismo progresista y democrático.

No obstante, como se ha tratado de demostrar a lo largo del presente trabajo, existen evidencias para afirmar que no fue un impuesto exclusivamente urbano ni únicamente una contribución sobre el gasto. Una de ellas es la propia caracteristica de la población espanola, mayoritariamente rural, y la distribución territorial de los cupos del impuesto, en la que los «pueblos» cargaban con la mayor parte, aunque, como se advirtió, no cabe identificar estrictamente este término de las estadísticas con medio rural. Un segundo dato es el testimonio de los contemporáneos, que insistian en que el tributo constituia un doble gravamen sobre la producción agraria. Esa afirmación tan reiterada a lo largo de más de medio siglo obliga a pensar que nos encontra. mos con algo más que con un tópico arbitrista o con un instrumento de defensa de los intereses directamente afectados. Una tercera evidencia, de la que los contemporáneos extraian sus conclusiones sobre la ruralidad del im. puesto, era el amplio recurso al reparto como medio para recaudarlo, por el que se percibió más del 25 por 100 de lo ingresado por este concepto duran. te la segunda mitad del xix. Ese repartimiento se hacia, al menos en algunos municipios, teniendo sólo en cuenta las inequitativas bases utilizadas para exigir la contribución territorial. Por último, los protagonistas campesinos de varios de los muchos motines son un indicativo de la incidencia aludida, y de la incapacidad, cuando eran ellos los que comercializaban la producción en los centros urbanos, de trasladar a corto plazo las tarifas del impuesto a los precios.

A estos pequeños productores también les cupo la posibilidad histórica de protagonizar, con los trabajadores urbanos, una de las fórmulas más llamativas de resistencia ante la Hacienda pública, resistencia que, con todo, no fue la más importante en términos presupuestarios. Ese protagonismo le correspondió al fraude y a la anticipación a las reformas tributarias o la contestación a las ya efectuadas, como sucedió en 1845.1846 con los Inquilinatos y la Contribución Industrial, o en 1899-1900 con los presupuestos y la reforma de Villa. verde. Son esos comportamientos, debidos a los denominados grupos de interés, los que contribuyen a explicar la insuficiencia del cuadro de impuestos, las rigideces para mejorar su administración y, en último término, la inequidad del sistema fiscal y el recurso a la financiación inflacionista de las obligaciones del Estado, que era también inequitativa. Esas actitudes insolidarias están, en fin, en la base de las circularidades viciosas en que se movió nuestra Hacienda pú. blica durante el siglo xix. 


\section{ARCHIVO}

1) Archivo del Congreso de los Diputados:

- Legajo 219, n." 102.

- Legajo 244, $n^{\circ}$. 226. "Dirección general de Impuestos. Estado del impuesto de Consumos en las capitales de provincias, tres puertos asimilados y poblaciones de más de treinta mil almas..." (1887), y «Dirección general de Impuestos. Estado del impuesto de Consumos en las poblaciones menores de treinta mil almas...» (1887).

- Legajo 247, n.". 30.

2) Archlo de la Camara Ohicial de Comercio, Industria y Navegacion de Vigo:

- Varios, Carpetas n.". 2 y n.". 3.

\section{BIBLIOGRAFIA}

Ályarez Rtnduelt.s, José Ramón (1976): «Antonio Flores de Lemus y la Comisión Extraparlamentaria para la transformación del impuesto de consumos», Hacienda Pública Española, 42-43, pp. 213.228.

- Anuario Estadistico de España $(1860,1866-1867,1870)$.

- Apuntes para el estudio del proyecto de ley sobre transformación del impuesto de consumos, presentado a las Cortes por el Sr. Ministro de Hacienda el dia 23 de octubre de 1906 (1907). 4 volúmenes, Madrid, Imprenta Hijos de J. A. Garcia.

Arrikro, Maria Luz (1984): «Los motines de subsistencias en España, 1895- 1905», Estudios de Historia Social, 30, pp. 193.250.

Artolı, Miguel (1986): La Hacienda del siglo xix. Progresistas y moderados, Madrid, Alianza.

BALIGAND, Albert von (1907, 1956): «El proyecto español de supresión de los impuestos de consumo estatales y municipales», Revista de Economía Política, vol. VII, 2-3, pp. $190-225$.

BeNall., Josep María (1985): «Politica i consums. La revolució del 1868 a Terrasa», Recerques, 17 , pp. $73 \cdot 103$.

Cabrera, Mercedes; Comix, Francisco, y Garcta Driciado, José Maria (1989): Santiago Alha. Un programa de reforma económica en el primer tercio del siglo $x x$, Madrid, IEF.

Calero, Antonio Maria (1976): Movimientos sociales en Andalucía (1820-1936), Madrid, Siglo XXI.

Cakk, Raimond (1992): España 1808-1975), Barcelona, Ariel.

Casroo, Demetrio (1991): «Protesta popular y orden público: los motines de consumos», en José Luis Garcia Delgado (ed.), España entre dos siglos (1875-1931). Continuidad y cambio, Madrid, Siglo XXI, pp. 109-123.

- Colección Legislativa de España $(1874,1885,1889,1899)$.

Comin, Francisco (1988): Hacienda y Economía en la España contemporánea (1800-1936). Madrid, IEF.

— (1990a): «Presentación», en Enrique Fuentes Quintana (1990), pp. VII-XXXIX.

- (1990b): «La politica fiscal en España entre 1874 y 1914: algunas precisiones», en José Luis Garcia Delgado (ed.), La España de la Restauración: politica, economía, legislación y cultura, Madrid, Siglo XXI, pp. 189-212. 
- (1994b): «La Deuda pública y la formación del sistema bancario en España durante los siglos XIX y xX», en Pedro Tedde y Carlos Marichal (coords.), La formación de los bancos centrales en España y América Latina (siglos $x x$ y $x X$ ). Vol. 1: España y México. Madrid, Banco de España-Servicio de Estudios. Estudios de Historia Económica, n." 29, pp. $49-79$.

- Comisión Extraparlamentaria para la transformación del impuesto de Consumos (19061910), 4 volúmenes, Madrid, Imprenta de la Sucesora de la sucesora de M. Minuesa de los Rios.

Costas Comesaña, Antonio (1988): Apogeo del liberalismo en "La Gloriosa». La reforma económica en el Sexenio liberal (1868-1874), Madrid, Siglo XXI.

CuBEL, Antonio (1994): La agricullura y el sistema fiscal español (1891-1935), Departament d'Anàlisi Econòmica. Universitat de Valencia.

- Diario de Sesiones del Congreso de los Diputados (1876, 1878, 1888).

- Diario de Sesiones del Senado (1892).

De. Diego Garcia, Emilio (1990): «La Hacienda madrileña en la Restauración (1875. 1881)", en Homenaje a los Profesores José M. Jover Zamora y Vicente Palacio Atard, t. 2, pp. 263-287.

Domingo Solans, Eugenio (1976): «La reforma de la Hacienda municipal de Flores de Lemus», Hacienda Pública Española, 42.43, pp. 229-265.

Dominc;uez Castro, Luis (1994): "Vino y política: la Junta de Defensa del Ribeiro en 1893", en XVI Jornadas de Viticultura y Enologia de Tierra de Barros (Almendralejo, 9.11 de mayo), pp. 851-862.

ElNaudi, Luigi (1968): Principios de Hacienda Pública, Madrid, Aguilar.

—_Estadistica Administrativa de la Dirección General de Contribuciones, 1855 (1855).

- Estadistica Tributaria de España (Ensayo Gráfico). Año económico 1894-95 (1897), Madrid, Imprenta de Ricardo Rojas.

Ffrnande. Cainzos, Juan J. (ed.) (1986): El Estado y los contribuyentes: La resistencia fiscal, Madrid, IEF.

FonTana, Josep (1981): Cambio económico y actitudes políticas en la España del siglo xix, Barcelona, Ariel.

Fuentes Quintana, Enrique (1990): Las reformas tributarias en España, Barcelona, Critica.

Garcla, Carmen, y Comin, Francisco (1995): «Reforma liberal, centralismo y Haciendas municipales en el siglo xıx», Hacienda Pública Española, 133, pp. 81-106.

Garcia Al.IX, Antonio (1907): El presupuesto de reconstrucción, Madrid, Establecimiento Tipográfico de Idamor Moreno.

Garcia Vinuei.a, Entique (1995): «Búsqueda de rentas a través del sector público», $\mathrm{Ha}$ cienda Pública Española, 133, pp. 106-114.

Garrido, Fernando (1881): La revolución en la Hacienda del Estado, las Provincias y los Municipios, Madrid, Imprenta de Enrique Vicente.

Gil NovalEs, Alberto (1986): «La conflictividad social bajo la Restauración (1875. 1917)», Trienio, 7, pp. 73-217.

Gonzdlez Besada, Augusto (1902): «La Hacienda», Nuestro Tiempo, año II, 17, pp. 754 803.

González Zúniga, Claudio (1854): Memoria sobre la industria agrícola, pecuaria, pesca, fabril y comercial de Galicia, Pontevedra, Imprenta de los SS. Antúnez y Pazos

Grupo de Estudios de Historia Rurai. (1988): «La crisis agricola en Castilla la Vieja y 
Andalucia: los casos del trigo y el olivar», en Ramón Garrabou (ed.), La crisis agraria de fines del $x i x$, Barcelona, Critica, pp. 35-68.

- La crisis agricola y pecuaria (1887-1889), Madrid, Tipografia de los «Sucesores de Rivadeneyra".

MALl.ADA, Lucas $(1890,1994)$ : Los males de la patria y la futura revolución española, Madrid, Alianza.

Martin Ackna, Pablo (1985): «Déficit público y politica monetaria en la Restauración, 1874-1923m, en P. Martin Aceña y L. Prados (eds.), La nueva Historia Económica de España, Madrid, Tecnos, pp. 262-284.

Martix Niño, Jesus (1972): La Hacienda Española y la Revolución de 1868, Madrid, IEF.

- (1981): «1854: una fecha en la historia del impuesto de consumos», Hacienda Pública Española, 69, 1981, pp. 219-228.

Martorfi. Linares, Miguel Ángel (1995): "La reforma pendiente. La Hacienda municipal en la crisis de la Restauración: el fracaso de la Ley de Supresión del Impuesto de Consumos», Hacienda Pública Española, 132, pp. 143. 152.

PAN-Montojo, Juan (1994a): «Lógica legal y lógica social de las contribución de consumos y derechos de puertasm, Hacienda Pública Española. Monografía, 1/1994, pp. 217.229 .

—. (1994b), La bodega del mundo. La vid y el vino en España (1800-1936), Madrid, Alianza/MAPA.

Pan-Montoro, Juan, y Puis; Nuria (1995): «Los grupos de interés y la regulación públjca del mercado de alcoholes en España (1887-1936)», Revista de Historia Económica, Año XIII, 2, pp. 251-280.

PARET, Lorenzo Victor (1914): Encarecimiento de la vida en los principales países de Europa y singularmente en España. Sus causas, Madrid, Establecimiento Tipográfico de Jaime Ratés.

Prert. Lfoesma, Manuel (1988): «Sociedad y conflicto social», en Miguel Artola (dir.), Enciclopedia de Historia de España, t. 1, Madrid, Alianza.

PIRRETAS, Marian (1900): El tancament de caixes, Barcelona.

Riu, Daniel (1918): "Causas del atraso industrial de España", Revista Nacional de Economí, 11, pp. 5-35.

Romero Mal'ra, Joaquin (1989): La rosa de fuego, Madrid, Alianza.

RUDE, George (1981): Revuelia popular y conciencia de clase, Barcelona, Critica.

SARDA, Juan (1948): La Política Monetaria y las fluctuaciones de la Economía española en el siglo XIX, Madrid, CSIC.

Sfrrano, Carlos (1981): "Guerra y crisis social: los motines de mayo del 98", Estudios sobre Historia de España (Homenaje a Tuñón de Lara), v. 1, Madrid, UIMP, pp. 439. 449.

- - (1987): Le tour du peuple. Crise nationale, mouvements populaires et populisme en Espagne (1890-1910), Madrid, Casa de Velázquez.

SERrano, Rafael (1987): «El retorno del impuesto de consumos en 1869.70 como via de financiación municipal: el caso de algunos ayuntamientos castellano leoneses», Investigaciones Históricas, 6, 1987, pp. 157- 167.

Tallada Paull., José Maria (1946): Historia de las finanzas españolas en el siglo XIX, Madrid, Espasa-Calpe.

Tedde de Lorca, Pedro (1984): «Aproximación al cuadro tributario de la Restauración», Hacienda Pública Española, 87, pp. 323-338. 
Tirado. Daniel A. (1994): «La protección arancelaria en la Restauracion. Nuevos indicadores", Revista de Economia Aplicada, 6, pp. 183-203.

Thompion, E. P. (1979): Tradición, revuelta y consciencia de clase, Barcelona, Critica.

Torras Elias, Jaime (1972): «En torno a la politica tributaria de los gobiernos del Trienio Constitucional (1820-1823", Moneda y Crédito, 122, pp. 153-170.

Torthilia Casares, Gabriel (1994): El desarrollo de la España contemporánea. Historia económica de los siglos XIX y XX, Madrid, Alianza.

Tunón de Lara, Manuel (1986): España: la quiebra de 1898, Madrid, Sarpe.

Vall.Fio Pousada, Rafael (1990): «Pervivencia de las formas tradicionales de protesta: los motines de 1892», Historia Social, 8, 1990, pp. 3- 27.

- (1994): «Fiscalidad y fraude fiscal en Galicia en la segunda mitad del siglo XIX», Hacienda Pública Española, Monografia 1/1994, Madrid, pp. 263-279.

VARELA ORTEGA, José (1994): «Sobre la naturaleza del sistema politico de la Restauración, en G. Gortazar (ed.), Nación y Estado en la España liberal, Madrid, Ed. Noesis, pp. 169-194.

Zurita, Rafael (1990): “Impuestos y revolución. El Ayuntamiento de Alicante ante la supresión de los consumos (1854-1856)», Hacienda Pública Española, 116-3/1990, pp. 203-211.

\section{PRENSA}

El Imparcial (1892).

El Liberal (1892).

El País $(1892,1902,1904)$.

El Socialista (1905).

La Correspondencia Gallega (1892).

La Unión Republicana (1892). 